Systematic Review

\title{
Comparison of Percutaneous Vertebroplasty and Balloon Kyphoplasty for the Treatment of Single Level Vertebral Compression Fractures: A Meta-analysis of the Literature
}

Hua Wang, MD, PhD, Shilabant Sen Sribastav, MD, Fubiao Ye, MD, PhD, Cangsheng Yang, MD, PhD, Jianru Wang, MD, PhD, Hui Liu, MD, PhD, and Zhaomin Zheng, MD, PhD

From: Department of Orthopaedics, First Affiliated Hospital of Sun

Yat-sen University, 58 Zhongshan Second Road, Guangzhou, P.R. China.

Address Correspondence: Dr. Zhaomin Zheng Department of Orthopaedic Surgery First Affiliated Hospital of Sun Yat-sen University 58 Zhongshan Second Road, Guangzhou, P.R. China. 510080 E-mail:

Zhengzm1@163.com

Hua Wang and Shilabant Sen Sribastav contributed equally to this work

Disclaimer: There was no external funding in the preparation of this manuscript.

Conflict of interest: Each author certifies that he or she, or a member of his or her immediate family, has no commercial association

(i.e., consultancies, stock ownership, equity interest, patent/licensing arrangements, etc.) that might pose a conflict of interest in connection with the submitted manuscript.

Manuscript received: o9-24-2014 Accepted for publication: 01-22-2015

Free full manuscript: www.painphysicianjournal. com
Background: Percutaneous vertebroplasty (PVP) and percutaneous balloon kyphoplasty (PKP) can increase bone strength as well as alleviate the pain caused by vertebral compression fractures (VCFs), and both procedures rely on polymethyl methacrylate (PMMA) cement injected into the fractured vertebra for mechanical stabilization of the VCFs. However, there is debate over which of these 2 surgical procedures can give better short-term and long-term outcomes. A lot of studies and meta-analysis were designed to assess the advantages and drawbacks of PKP and PVP in the treatment of VCFs, but most of them didn't consider the effect of VCF levels on the treatment outcome, which can influence the results.

Objective: To assess the safety and efficacy of PKP compared to PVP in the treatment of single level osteoporotic vertebral compression fractures (OVCF).

Study Design: Studies with the following criteria were included: patients with VCFs due to osteoporosis; PKP comparing PVP; study design, RCT or prospective or retrospective comparative studies. Furthermore, the studies which reported at least one of the following outcomes: subjective pain perception, quality of life evaluation, incidence of new adjacent vertebral fracture, bone cement leakage, and post-operative kyphotic angle. Articles were excluded in our meta-analysis if they had a neoplastic etiology (i.e., metastasis or myeloma), infection, neural compression, traumatic fracture, neurological deficit, spinal stenosis, severe degenerative diseases of the spine, previous surgery at the involved vertebral body, and PKP or PVP with other invasive or semi-invasive intervention treatment.

Setting: University hospital.

Methods: A systematic search of all articles published through May 2014 was performed by Medline, EMASE, OVID, and other databases. All the articles that compared PKP with PVP on single level OVCF were identified. The evidence quality levels of the selected articles were evaluated by Grade system. Data about the clinical outcomes and complications were extracted and analyzed.

Results: Eight studies, encompassing 845 patients, met the inclusion criteria. Overall, the results indicated that there were significant differences between the 2 groups in the short-term visual analog scale (VAS) scores, the long-term Oswestry Disability Index (ODI), short- and long-term kyphosis angle, the kyphosis angle improvement, the injected cement, and the cement leakage rates. However, there were no significant differences in the long-term VAS scores, the short-term ODI scores, the short- and long-term SF-36 scores, or the adjacent-level fracture rates.

Limitations: Statistical efficacy can be improved by more studies, low evidence based non-RCT articles are likely to induce various types of bias, no accurate definition of short-term and long-term outcome time points.

Conclusion: PKP and PVP are both safe and effective surgical procedures in treating OVCF. PKP has a similar long-term pain relief, function outcome (short-term ODI scores, short-and long-term SF-36 scores), and new adjacent VCFs in comparison to PVP. PKP is superior to PVP for the injected cement volume, the short-term pain relief, the improvement of short- and long-term kyphotic angle, and lower cement leakage rate. However, PKP has a longer operation time and higher material cost than PVP. To confirm this evaluation, a large multi-center randomized controlled trial (RCT) should be conducted.

Key words: Percutaneous, kyphoplasty, vertebroplasty, osteoporosis vertebral compression fracture, pain, meta-analysis

Pain Physician 2015; 18:209-221 
T he prevalence of osteoporosis increases with the increasing age of the population. Osteoporosis can lead to osteoporotic vertebral compression fractures (OVCF), and it is the major health problem of older people worldwide. In addition to osteoporosis, causes of VCFs also include hemagioma, multiple myeloma, and metastasis. Nearly 700,000 OVCFs occur annually in the United States (1). Approximately $8 \%$ of women over 50 years old and $27 \%$ of women over 80 years old are presented with VCFs (2). Due to VCFs, the patients suffer severe chronic pain, kyphosis, compromised mobility, pulmonary function reduction (3), as well as high mortality (4). Historically, surgical treatment was indicated in VCF patients with neurologic deficit or spinal instability (5). As open surgery also has great risk for these older VCF patients with multiple medical comorbidities, conservative treatment is considered for the VCF patients with bed rest, analgesics, and bracing. However, conservative management with long periods of inactivity in elderly patients can lead to pneumonia, decubitus ulcers, venous thromboembolism, new VCFs, and even death (6). High VCF-related morbidity and treatment costs for VCF demand finding the alternative treatments that would be less invasive than open surgery and more effective than conservative management (7).

Two minimally invasive spine augmentation techniques were found to fulfill this demand, percutaneous vertebroplasty (PVP) (8) and percutaneous balloon kyphoplasty (PKP) (9). Both procedures rely on polymethyl methacrylate (PMMA) cement injection into the fractured vertebra for mechanical stabilization of the VCF. Both PVP and PKP can increase bone strength as well as alleviate the pain caused by VCFs. Vertebroplasty is the percutaneous injection into the vertebral body with bone cement (generally PMMA, which has been used in orthopedic procedures since the late 1960s). PVP for the treatment of painful hemangiomas was first introduced by Galibert et al (8) in 1987. After that many surgeons have advocated and expanded the indications for PVP to include osteoporotic compression fractures, traumatic compression fractures, and painful vertebral metastasis.

PKP is the modification of the PVP procedure, first developed by Reiley et al in 1998, and then forwarded by Belkoff et al in 2001(10). PKP was introduced to manage the kyphotic deformity and restore the vertebral height. PKP involves the percutaneous placement of an inflatable balloon device (bone tamp) into a vertebral body. The inflation of the bone tamp by radio-opaque liquid restores the vertebral height and helps correct the kyphotic deformity. After deflation, PMMA is injected in the cavity made by the balloon device. Initially it was reserved for tumoral and osteoporotic lesions, and later gradually established its role in the treatment of vertebral fractures (11). The advantage of PVP/PKP in comparison to conservative management or open surgery has been well established in terms of pain and functional outcome $(12,13)$. Cement injection into the vertebra may have an analgesic effect by fixing microfractures and decreasing the mechanical stress associated with weight and activity, and also during cement polymerization nerve endings of bone are destroyed by cytotoxic and exothermal action, which help in reducing pain (14).

A previous meta-analysis recommended PVP over PKP for treating VCFs when considering the higher cost of the PKP procedure (15). However, there is debate over which of these 2 surgical procedures can give better short-term and long-term outcomes. A lot of studies and meta-analysis were designed to assess the advantages and drawbacks of PKP and PVP in the treatment of VCFs, but most of them didn't consider the effect of VCF levels on the treatment outcome, which can influence the results. In this study, we conduct a systematic review and meta-analysis of the available literature to assess the safety and efficacy of PKP compared to PVP in the treatment of single level VCFs.

\section{Methods}

\section{Search Strategy}

We conducted a computerized search of the electronic databases like OVID MEDLINE, PubMed, ISI Web of Knowledge, Embase, ScienceDirect, Google Scholar, and the Cochrane Central Register of Controlled Trials (CENTRAL) until the end of April 2014, according to the PRISMA (Preferred Reporting Items for Systematic Reviews and Meta-Analyses) for published studies comparing PKP with PVP in patients with VCFs. The following key terms were used for the database research: balloon kyphoplasty, vertebroplasty, vertebral compression fracture, and osteoporosis. Secondary searches of unpublished literature were conducted by searching the WHO International Clinical Trials Registry Platform, the UK National Research Register Archive, and Current Controlled Trials until the end of April 2014. Conference proceedings, such as the European Federation of National Associations of Orthopaedics and Traumatology, British Orthopaedic Association Annual Congress, 
and the ISTP database, were also searched for entries up to May 2014. The references of these articles were also searched to identify any additional studies not previously identified in the initial literature search. There was a restriction on the publication language, i.e., only English language publications were selected.

\section{Inclusion Criteria}

Studies with the following criteria were included: patients with VCFs due to osteoporosis; PKP comparing PVP; study design, randomized controlled trials (RCT) or prospective or retrospective comparative studies. Furthermore, the studies which reported at least one of the following outcomes: subjective pain perception, quality of life evaluation, incidence of new adjacent vertebral fracture, bone cement leakage, and post-operative kyphotic angle.

\section{Exclusion Criteria}

Articles were excluded in our meta-analysis if they had a neoplastic etiology (i.e., metastasis or myeloma), infection, neural compression, traumatic fracture, neurological deficit, spinal stenosis, severe degenerative diseases of the spine, previous surgery at the involved vertebral body, and PKP or PVP with other invasive or semi-invasive intervention treatment.

\section{Data Extraction}

Two reviewers independently screened the title and abstract related to the inclusion criteria. Full-text reading of the literature was performed for the final inclusion. We resolved disagreements by discussion with a third author. Again 2 authors independently extracted the following data: study characteristics, types of interventions, surgical procedures, and outcome parameters. The extracted data were rechecked by a third author.

\section{Outcome}

The clinical outcomes included the visual analog scale (VAS), Oswestry Disability Index (ODI), Short Form-36 (SF-36), and the volume of injected cement. Radiographic outcomes included the kyphosis angle and the anterior vertebral body height. Complication outcomes were adjacent vertebral fractures and bone cement leakage. In addition, we defined the short-term time point as no more than one week and the longterm time point as more than 6 months. If there were no reported data at those time points, we used data from the time point closest to our time points.

\section{Assessment of Methodological Quality}

The methodological quality of the included studies was independently assessed by 2 reviewers (according to the Cochrane Handbook for Systematic Reviews of Interventions 5.0). Any disagreement was resolved by a third reviewer. The included RCT was evaluated for risk of bias, which included adequate sequence generation, allocation of concealment, blinding, incomplete outcome data, and freedom from other biases.

\section{Data Analysis and Evidence Synthesis}

We performed all meta-analyses with RevMan Version 5.1 (The Cochrane Collaboration, Copenhagen, Denmark). For continuous outcomes, means and standard deviations were pooled to a mean difference (MD) and a 95\% confidence interval (Cl). For dichotomous outcomes, the risk ratio (RR) and the $95 \% \mathrm{Cl}$ were assessed. A probability of $P<0.05$ was regarded as statistically significant. The assessment for statistical heterogeneity was calculated using the chi-square and I-square tests. The source of heterogeneity was investigated by a subgroup analysis and a sensitivity analysis. In this meta-analysis, the subgroup analysis was performed according to the short-term and longterm follow-up. The sensitivity analysis was performed by rejecting the study with the higher statistical heterogeneity.

\section{Results}

\section{Search Results}

A total of 277 citations were reviewed. All the articles were selected strictly according to the criteria described. Of the total 277 titles and abstracts reviewed, 8 studies (16-23) met the inclusion criteria eventually. These studies included one RCT study (17), 4 prospective cohort studies $(18,20,22,23)$, and 3 retrospective cohort studies $(16,19,21)$. In total, 845 patients and 845 vertebral bodies were included in the 8 studies. The study selection process and reasons for exclusion are summarized in Fig. 1.

\section{Quality Assessement}

Eight articles directly comparing PVP and PKP were included in this meta-analysis: one RCT, 4 prospective cohort studies, and 3 retrospective cohort studies. The risk of bias assessment is shown in Table 1. All the articles evaluated the safety and efficacy of PKP and PVP in the treatment of OVCFs. The sample sizes of the included studies ranged from 20 to 148 . These stud- 


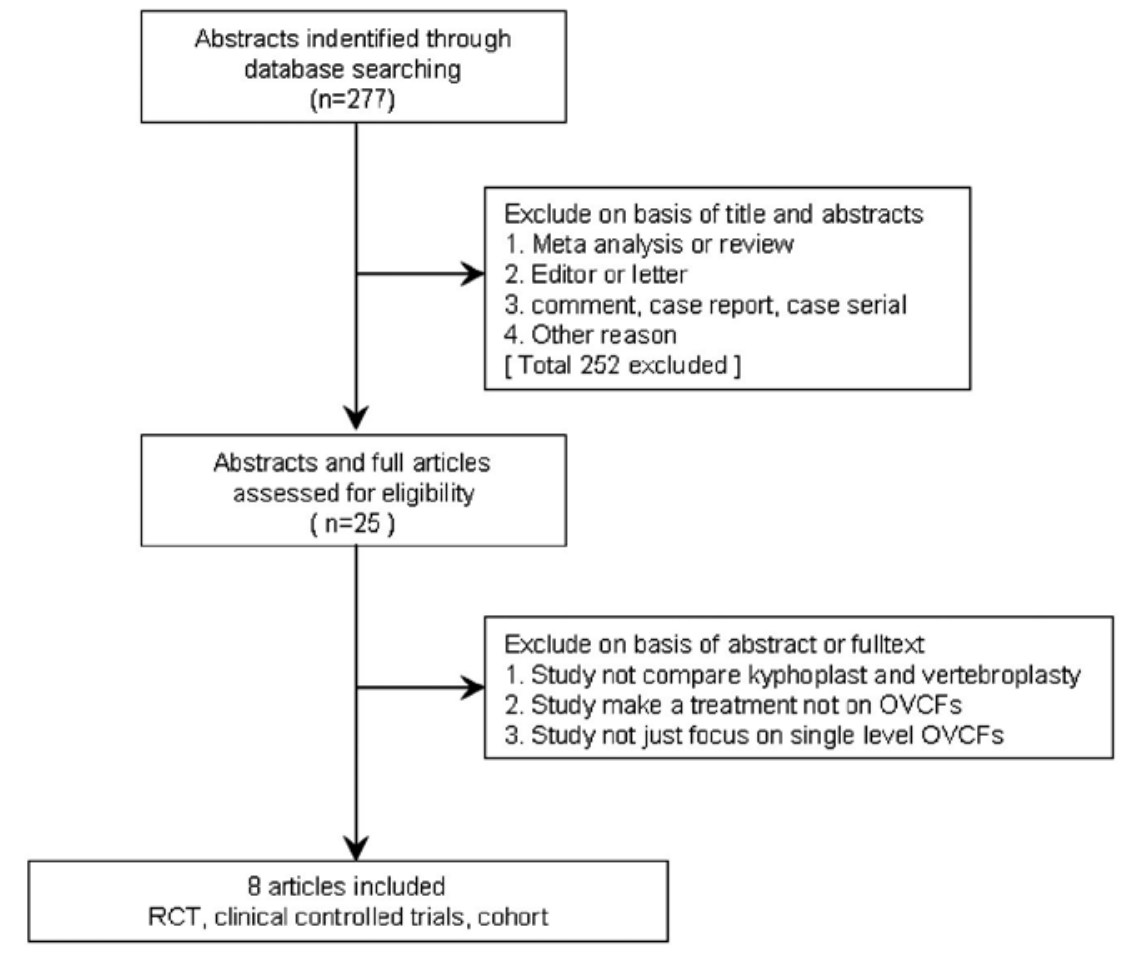

Fig. 1. Summary of the article selection and exclusion process.

Table 1. The study designs and MINORS appraisal scores for the non-RCTs.

\begin{tabular}{|c|c|c|c|c|c|c|c|c|c|c|c|c|c|c|}
\hline \multirow{2}{*}{ Study } & \multirow{2}{*}{ Study design } & \multicolumn{12}{|c|}{ MINORs methodological criteria } & \multirow{2}{*}{ Total } \\
\hline & & 1 & 2 & 3 & 4 & 5 & 6 & 7 & 8 & 9 & 10 & 11 & 12 & \\
\hline Zhou et al (15) & Retrospective cohort & 2 & 0 & 0 & 1 & 0 & 1 & 0 & 0 & 2 & 1 & 0 & 1 & 8 \\
\hline Schofer et al (17) & CCT & 2 & 1 & 1 & 2 & 0 & 2 & 1 & 0 & 2 & 2 & 1 & 1 & 15 \\
\hline Yan et al (18) & Retrospective cohort & 2 & 0 & 0 & 1 & 0 & 2 & 1 & 0 & 2 & 2 & 0 & 1 & 11 \\
\hline Endres et al (19) & Prospective cohort & 2 & 0 & 1 & 1 & 0 & 2 & 2 & 0 & 2 & 2 & 0 & 1 & 13 \\
\hline Kong et al (20) & Retrospective cohort & 2 & 1 & 0 & 1 & 0 & 2 & 0 & 0 & 2 & 2 & 2 & 1 & 13 \\
\hline Omidi-Kaskani et al (21) & Prospective cohort & 2 & 1 & 1 & 1 & 0 & 2 & 1 & 0 & 2 & 2 & 2 & 1 & 15 \\
\hline Ee et al (22) & Prospective cohort & 2 & 1 & 1 & 1 & 0 & 2 & 1 & 0 & 2 & 2 & 0 & 1 & 13 \\
\hline
\end{tabular}

The MINORs criteria include the following items: 1 . a clear stated aim; 2. inclusion of consecutive patients; 3 . prospective data collection; 4 . endpoints appropriate to the aim of the study; 5 . unbiased assessment of the study end point; 6 . a follow-up period appropriate to the aims of the study; 7 . less than $5 \%$ loss to follow-up; 8 . prospective calculation of the sample size; 9 . an adequate control group; 10 . contemporary groups; 11 . baseline equivalence of groups; and 12. adequate statistical analysis.

The items are scored as follows: 0 (not reported); 1 (reported but inadequate); 2 (reported and adequate). The ideal score for comparative studies is 24 .

ies only focus on the treatment of single level OVCFs. PMMA was the only type of cement for the treatment, but the volume varied greatly.

Only one trial (20) reported an adequate sequence generation, and one trial (18) reported allocation con- cealment. One study (20) reported using single-blinded outcome assessors, and no studies reported using double-blinded assessors; the other studies did not specify a blinding method. The methodological quality of the RCT is presented in Table 2 . The methodological quality 
Table 2. Quality assessment of the RCT study.

\begin{tabular}{|l|l|l|l|l|l|l|l|}
\hline Study & $\begin{array}{l}\text { Random } \\
\text { sequence } \\
\text { generation }\end{array}$ & $\begin{array}{l}\text { Allocation } \\
\text { concealment }\end{array}$ & $\begin{array}{l}\text { Blinding of } \\
\text { participants and } \\
\text { personnel }\end{array}$ & $\begin{array}{l}\text { Blinding } \\
\text { of outcome } \\
\text { assessment }\end{array}$ & $\begin{array}{l}\text { Incomplete } \\
\text { outcome data }\end{array}$ & $\begin{array}{l}\text { Selective } \\
\text { reporting }\end{array}$ & Other bias \\
\hline Liu et al (16) & Low risk & High risk & Unclear risk & Unclear risk & Low risk & Unclear risk & Unclear risk \\
\hline
\end{tabular}

Table 3. The demographic characteristics of the included studies.

\begin{tabular}{|c|c|c|c|c|c|c|c|c|c|c|}
\hline \multirow[t]{2}{*}{ Reference } & \multirow[t]{2}{*}{ Country } & \multicolumn{2}{|c|}{$\begin{array}{c}\text { Sample size } \\
(\mathbf{M} / \mathbf{F})\end{array}$} & \multicolumn{2}{|c|}{ Age (years) } & \multicolumn{2}{|c|}{$\begin{array}{c}\text { Levels of } \\
\text { VCF }\end{array}$} & \multicolumn{2}{|c|}{$\begin{array}{c}\text { Cement Volume } \\
(\mathrm{ml})\end{array}$} & \multirow{2}{*}{$\begin{array}{l}\text { Follow-up } \\
\text { PKP/PVP }\end{array}$} \\
\hline & & PKP & PVP & PKP & PVP & PKP & PVP & PKP & PVP & \\
\hline Zhou et al (15) & China & $\begin{array}{c}42 \\
(17 / 25) \\
\end{array}$ & $\begin{array}{c}56 \\
(21 / 35) \\
\end{array}$ & 64 (average) & 62 (average) & 42 & 56 & NR & NR & $12 / 12$ \\
\hline Schofer et al (17) & Germany & $\begin{array}{c}30 \\
(22 / 8) \\
\end{array}$ & $30(24 / 6)$ & $72.5 \pm 15.7$ & $73.8 \pm 6.4$ & 30 & 30 & $4.9 \pm 1.2$ & $3.9 \pm 1.5$ & $\begin{array}{l}13.5+6.9 / \\
13.7+7.1 \\
\end{array}$ \\
\hline Liu et al (16) & Taiwan & $\begin{array}{c}50 \\
(11 / 39) \\
\end{array}$ & $\begin{array}{c}50 \\
(12 / 38) \\
\end{array}$ & $72.3 \pm 7.6$ & $74.3 \pm 6.4$ & 50 & 50 & $\begin{array}{c}5.56 \pm \\
0.62 \\
\end{array}$ & $\begin{array}{c}4.91 \pm \\
0.65 \\
\end{array}$ & $6 / 6$ \\
\hline Yan et al (18) & China & $\begin{array}{c}98 \\
(57 / 41) \\
\end{array}$ & $\begin{array}{c}94 \\
(55 / 39) \\
\end{array}$ & $\begin{array}{c}76.89 \pm \\
11.52 \\
\end{array}$ & $\begin{array}{c}77.16 \pm \\
10.34\end{array}$ & 98 & 94 & $\begin{array}{c}4.5 \pm 0.8 \\
(3-6) \\
\end{array}$ & $\begin{array}{c}3.4 \pm 1.5 \\
(1-5) \\
\end{array}$ & $12 / 12$ \\
\hline Endres et al (19) & Germany & $\begin{array}{c}20 \\
(6 / 14) \\
\end{array}$ & $20(8 / 12)$ & $\begin{array}{c}63.3(53 \\
-77) \\
\end{array}$ & $\begin{array}{c}71.3(63 \\
-77) \\
\end{array}$ & 20 & 20 & $3.9(3-5)$ & $3.1(2-4)$ & $6 / 6$ \\
\hline Kong et al (20) & China & $\begin{array}{c}29 \\
(7 / 22) \\
\end{array}$ & $24(8 / 16)$ & $71.9 \pm 7.0$ & $70.5 \pm 6.4$ & 29 & 24 & $7.2 \pm 1.3$ & $5.2 \pm 1.2$ & $12 / 12$ \\
\hline $\begin{array}{l}\text { Omidi-Kashani } \\
\text { et al (21) }\end{array}$ & Iran & $\begin{array}{c}29 \\
(7 / 22) \\
\end{array}$ & $28(6 / 22)$ & $72.1 \pm 6.2$ & $72.4 \pm 8.2$ & 29 & 28 & $5.1 \pm 0.9$ & $3.5 \pm 0.4$ & $6 / 6$ \\
\hline Ee et al (22) & Singapore & $\begin{array}{c}97 \\
(10 / 87)\end{array}$ & $\begin{array}{c}148 \\
(24 / 124)\end{array}$ & $75 \pm 11$ & $77 \pm 8$ & 97 & 148 & NR & NR & $24 / 24$ \\
\hline
\end{tabular}

$\mathrm{M}=$ male, $\mathrm{F}=$ female, $\mathrm{PKP}=$ kyphoplasty, $\mathrm{PVP}=$ vertebroplasty, $\mathrm{NR}=$ not reported, age and volume of injected cement was described as mean \pm $\mathrm{SD}$ or mean (range), cement volume $=$ injected cement volume, follow-up (months)

of the included non-RCTs was assessed by MINORs quality scores, shown in Table 1. The mean score was 13.7 (range, $13-15$ ). This indicated that there was considerable variability in the evidence base.

\section{Demographic Characteristics}

In total, one RCT, 4 prospective cohort studies, and 3 retrospective cohorts with 231 men and 614 women were eligible for inclusion. Three hundred ninety-five patients underwent PKP and 450 patients underwent PVP. All of the included studies had defined eligibility criteria, and recruited patients with the following attributes: (1) single level VCFs; (2) moderate to severe pain caused by a radiological compression fractures; (3) no neurological deficits, no systemic or spinal infections, no pathologic fractures; and (4) no osteomalacia or vertebral metastases. One of the included studies only recruited fresh VCF patients and defined fresh VCFs as no more than 28 days after the fracture. The demographic characteristics of these studies are shown in Table 3.

\section{Pain}

The pain intensity measured by VAS score was extracted and summarized as short-term and long-term follow-up; we pooled the outcome values by subgroup analysis. None of the articles reported significant differences between PKP and PVP in VAS score pre-operation, but PKP groups has significantly lower VAS scores in the short-term post-operation follow-up (MD $=-0.27,95 \%$ $\mathrm{Cl}=-0.37$ to $-0.17, P<0.01$ ), which showed that the pain relief after PKP treatment was superior to PVP at shortterm follow-up. Long-term VAS scores were available for 5 articles, the results demonstrated no significant difference between PKP and PVP (MD $=-0.02,95 \% \mathrm{Cl}=$ -0.18 to $0.13, P=0.77$ ) (Fig. 2).

\section{Function}

Three articles presented functional parameters, the ODI data, the subgroup analysis was performed as short-term and long-term follow-up. Three articles reported short-term ODI scores. The results showed 


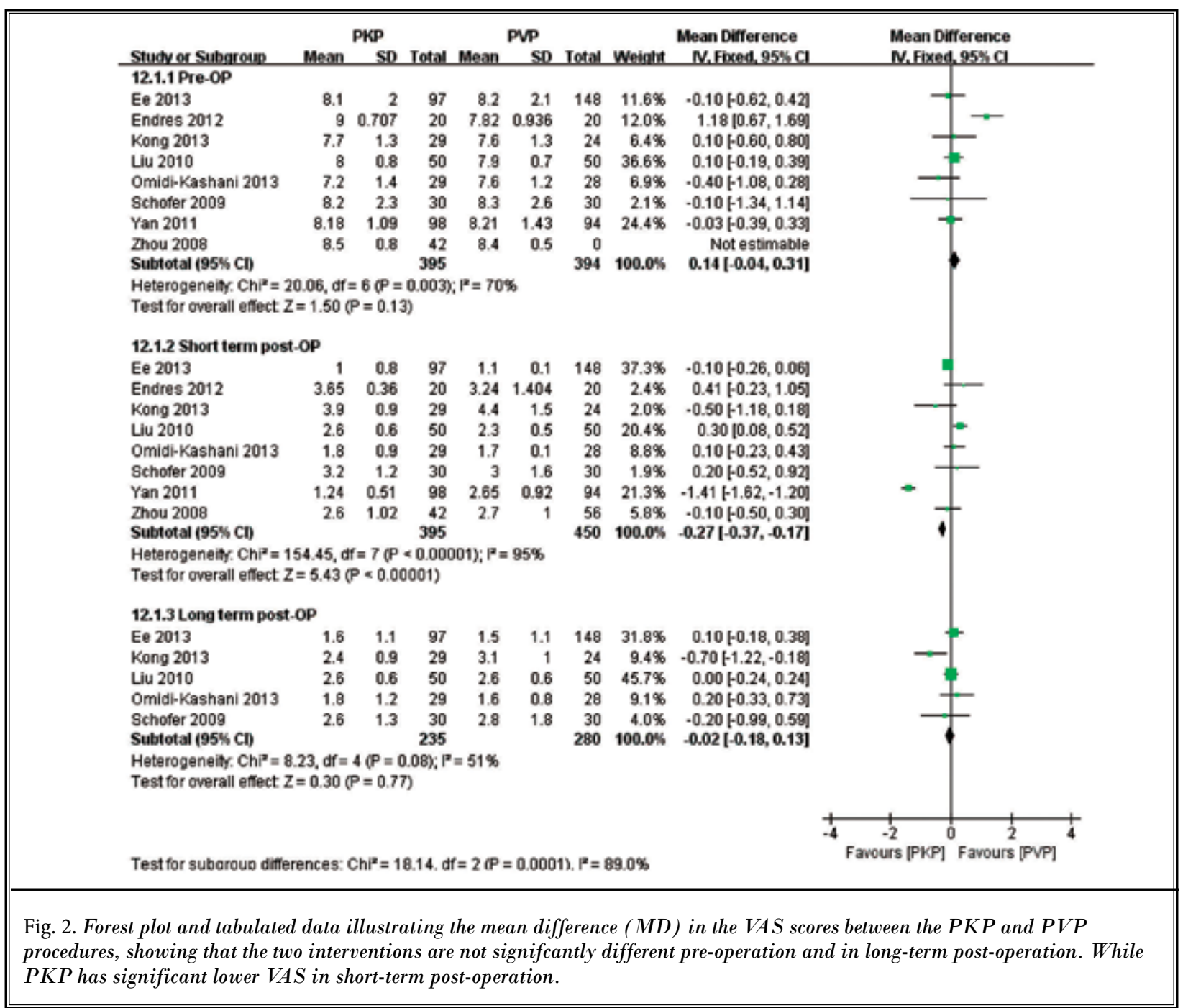

no significant difference between PKP and PVP (MD $=-2.59,95 \% \mathrm{Cl}=-5.51$ to $0.34, \mathrm{P}=0.08)$. Two articles reported long-term ODI scores. The results showed that patient function recovery after PKP treatment was superior to PVP in ODI at long-term follow-up ( $M D=$ $-3.49,95 \% \mathrm{Cl}=-6.63$ to $-0.66, \mathrm{P}=0.02$ ). (Fig. $3 \mathrm{~A}$ )

Two articles provided SF-36 data; the subgroup analysis was performed according to short-term and long-term follow-up. In short-term follow-up, an overall pooled $\mathrm{WMD}$ value $(\mathrm{MD}=1.42,95 \% \mathrm{Cl}=-0.98$ to $3.81, P=0.25$ ) was obtained, which indicated there was no significant difference between PKP and PVP for the functional improvement of patients with VCFs. Similar results were shown at the long-term follow-up too, with an overall pooled $\mathrm{WMD}$ value $(\mathrm{MD}=3.04,95 \%$ $\mathrm{Cl}=-0.15$ to $6.23, P=0.06)$. There is no significant dif- ference between PKP and PVP for short- and long-term functional improvement (Fig. 3B).

The data of the cement injected into the vertebra were available for 6 studies. The pooled results showed that the volume of injected cement in PKP groups was significantly more than PVP groups (MD $=1.00,95 \% \mathrm{Cl}$ $=0.86$ to $1.15, P<0.01$ ) (Fig. 4A).

The time of operation was available for 3 trials. The pooled results showed the duration of operation in PVP groups was significantly shorter than PKP groups (MD = $4.57,95 \% \mathrm{Cl}=3.29$ to $5.85, P<0.01$ ) (Fig. 4B).

\section{Complications}

Cement leakage and new adjacent level VCFs were the most common complications in the included studies; the related data were extracted and summarized 


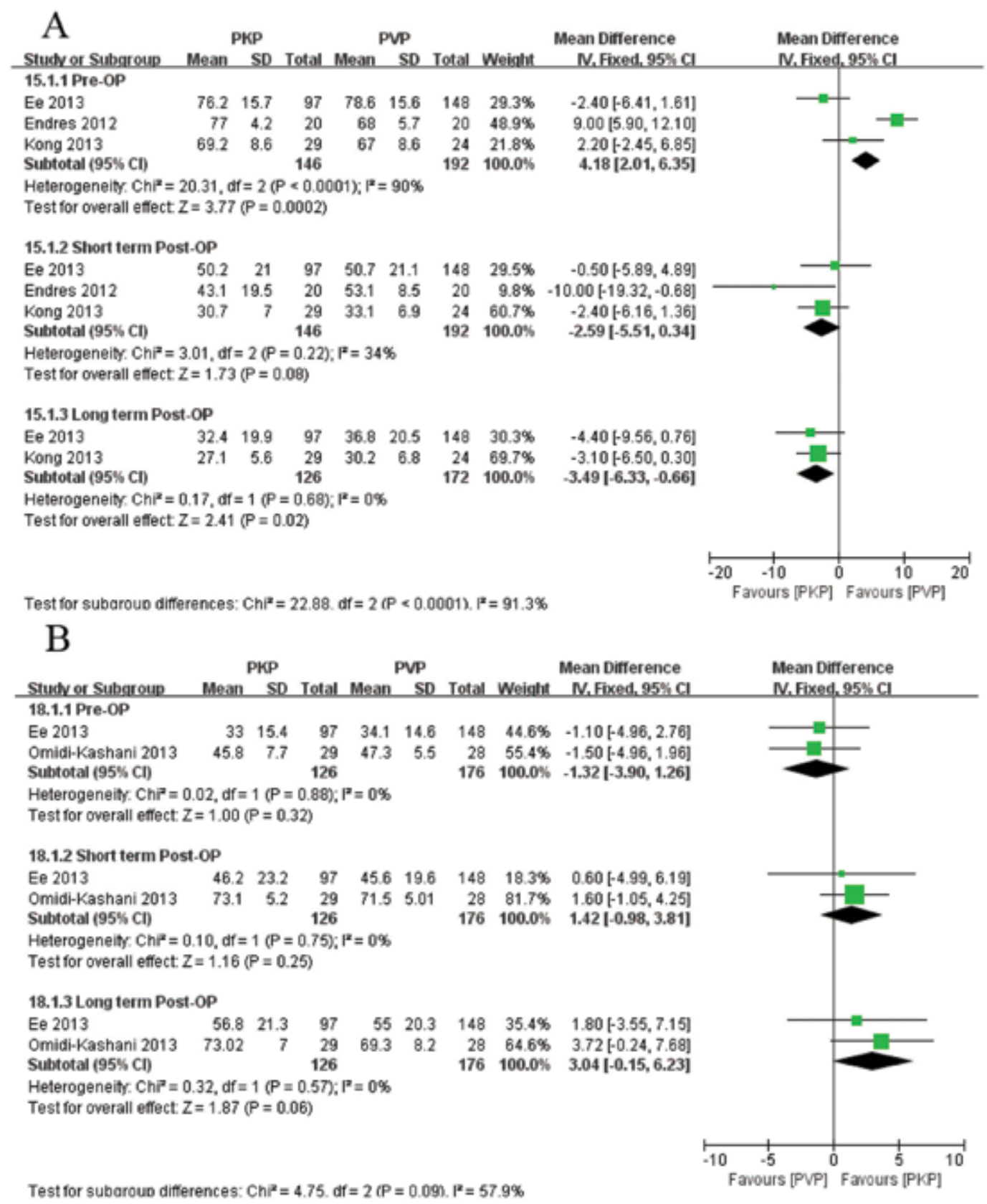

Fig. 3 A) Forest plot and tabulated data illustrating the MD in the ODI scores between the PKP and PVP procedures, showing that PKP has significant lower ODI socre in long-term follow-up post-operation. B) The SF-36 scores between the PKP and $P V P$ procedures, showing that the two intervention are not significant different.

for the safety assessment of PKP and PVP treatment.

Six studies provided information about complications related to cement leakage. The pooled analysis indicated that PKP had a lower incidence of cement leakage and was therefore superior in this aspect $(R R=$ $0.34,95 \% \mathrm{Cl}=0.21$ to $0.55 ; P<0.01$ ) (Fig. $5 \mathrm{~A}$ ). 

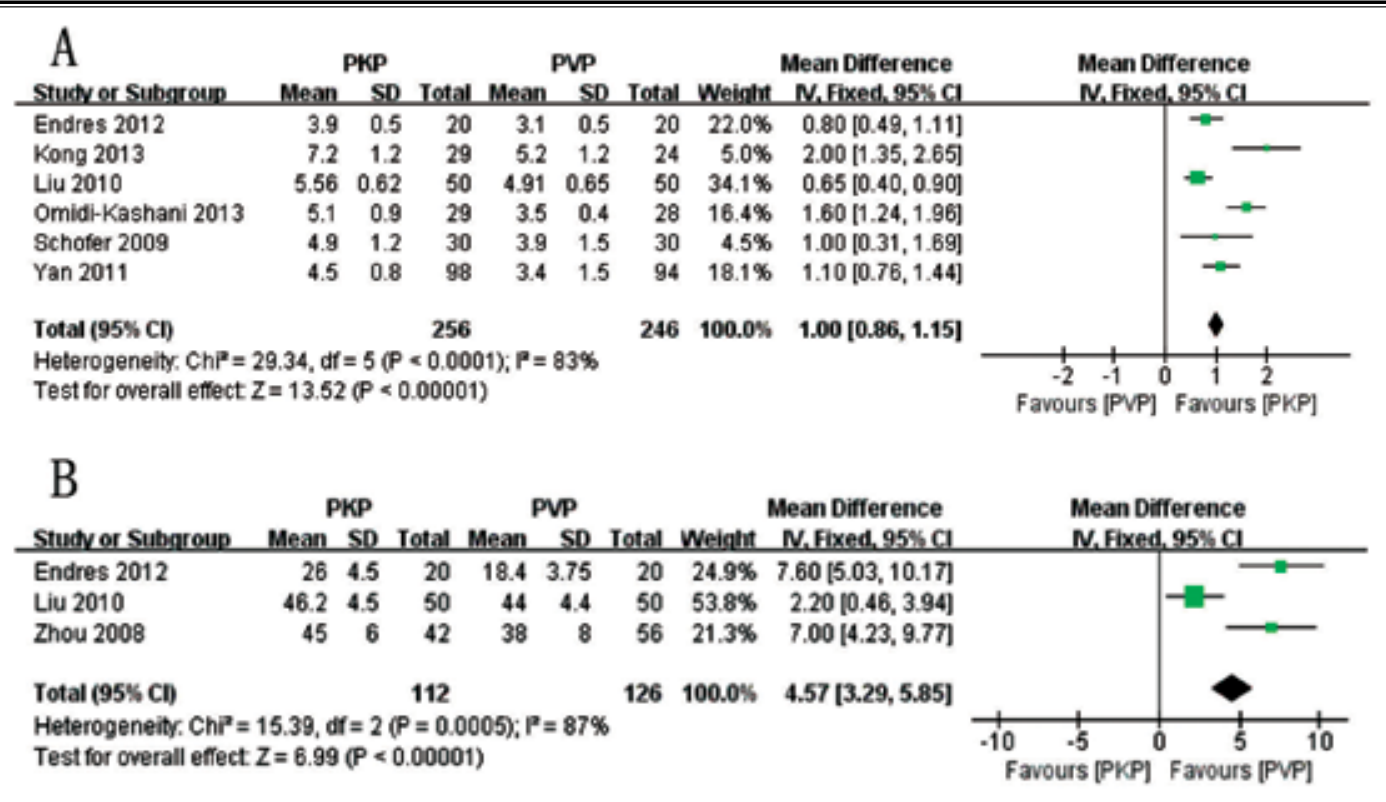

Fig. 4 A) Forest plot and tabulated data illustrating the volume of cement injection between the PKP and PVP procedures, showing that PKP has a significant more cement injection than PVP and is therefore superior in this respect. B) The operation time between the PKP and PVP procedures, showing that PVP has a significant shorter operation time than PVP and is therefore superior in this respect.

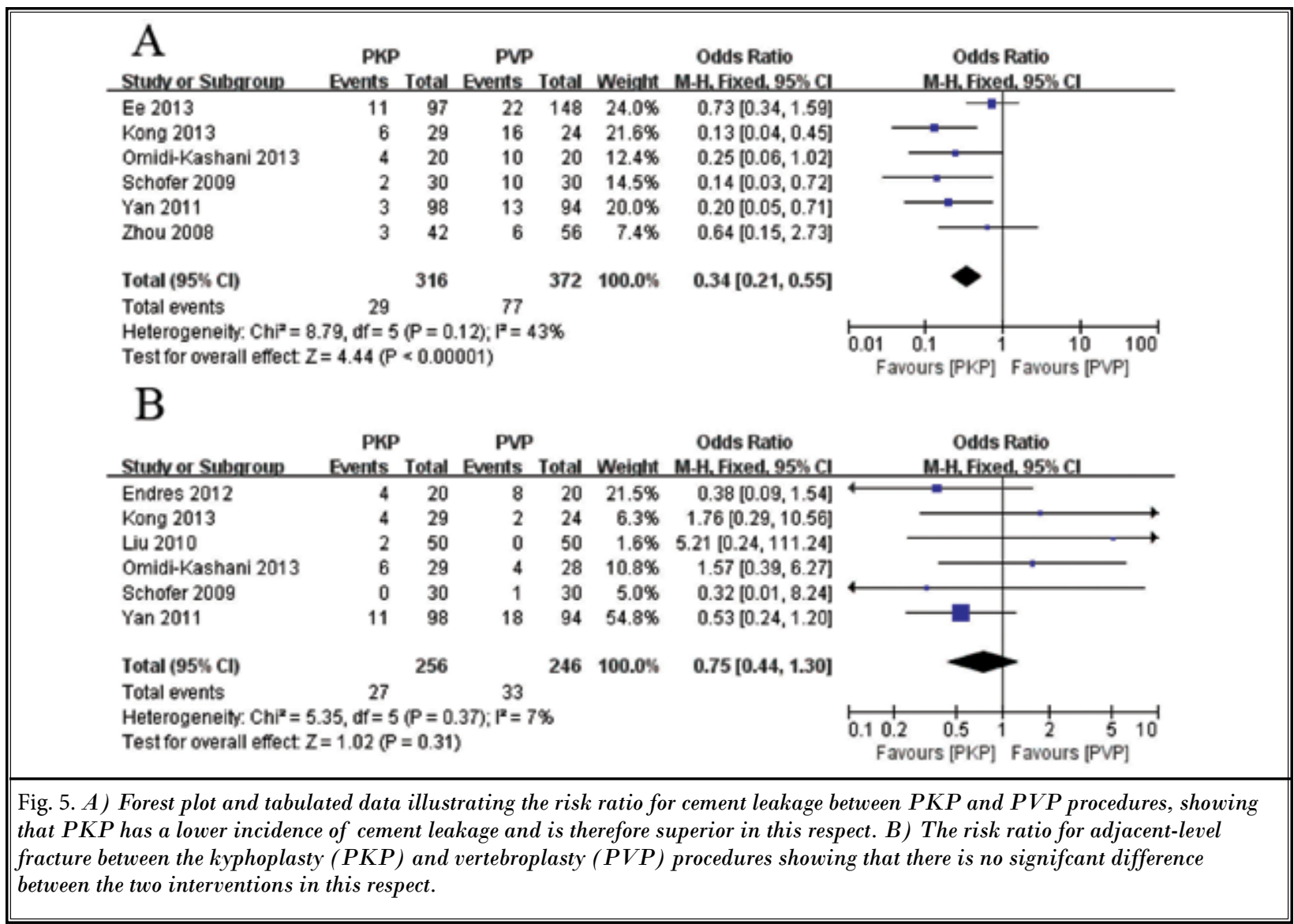




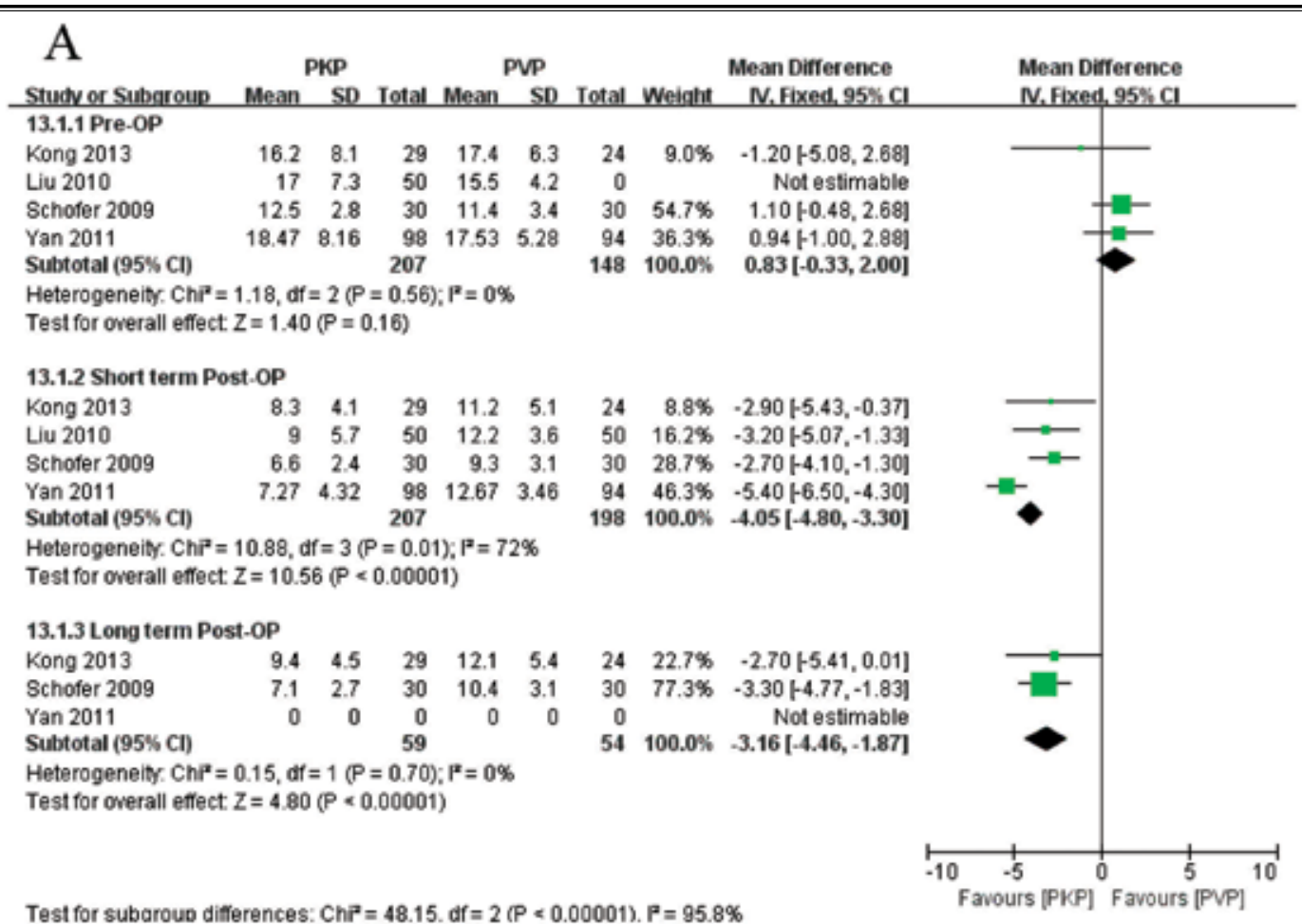

B

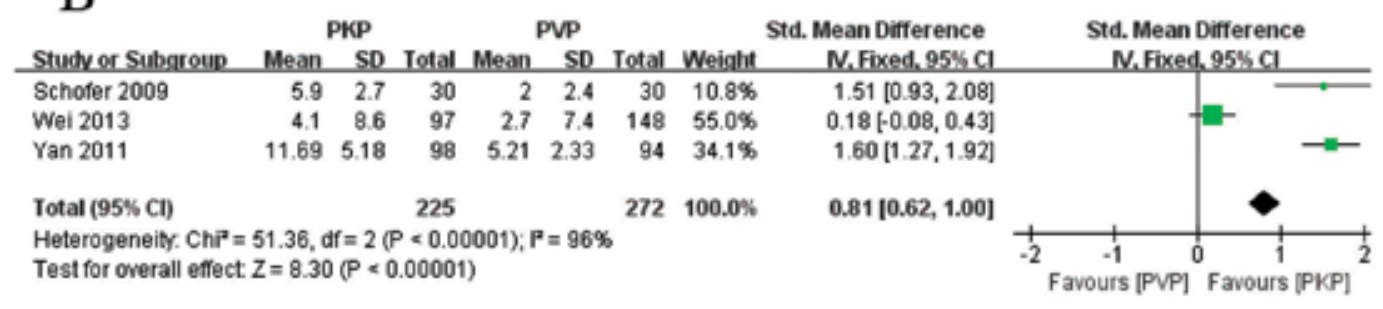

Fig. 6. A) Forest plot and tabulated data illustrating the MD in post operative kyphosis angle between the PKP and PVP procedures, showing that patients who underwent PKP had a better kyphosis angle than patients who underwent PVP in kyphosis angle postoperatively in the short/long-term follow-up post-operation. B) The MD in kyphosis angle improvement between PKP and PVP procedures, showing that patients who underwent PKP had a better kyphosis angle improvement than patients who underwent PVP.

Six studies provided data about risk ratio for adjacent VCFs. The pooled analysis showed that there was no significant difference between the 2 interventions in incidence of adjacent VCFs ( $R R=0.75,95 \% \mathrm{Cl}=0.44$ to 1.30; $P=0.31$ ) (Fig. 5B).

\section{Radiographic Outcomes}

The local kyphosis angle after operation was evaluated in both short-term and long-term follow-up. A subgroup analysis was performed for the study design subgroups. Four studies reported short-term kyphosis angle postoperatively and 3 studies provided data on long-term kyphosis angle postoperatively. The results showed patients who underwent PKP had better kyphosis angle outcome than patients who underwent PVP in the short-term (MD $=-4.05,95 \% \mathrm{Cl}=-4.80$ to $-3.30, P<0.01)$ and long-term follow-up (MD = -3.16, $95 \% \mathrm{Cl}=-4.46$ to $-1.87, P<0.01$ ) (Fig. $6 \mathrm{~A}$ ).

Three studies reported information on postoperative kyphosis angle improvement between the PKP and PVP. The pooled results showed that patients who underwent PKP had a better kyphosis angle improvement 
than patients with PVP (MD $=0.81,95 \% \mathrm{Cl}=0.62$ to 1.00, $P<0.01$ ) (Fig. 6B).

\section{Discussion}

To our knowledge, this is the first meta-analysis of studies comparing the effect of PKP and PVP for the treatment of single level VCFs. The prevalence of osteoporosis is increasing due to the increasing age of the population, causing a major health problem worldwide. PKP and PVP provide alternatives for patients that conservative treatment couldn't. They are minimally invasive procedures and can provide rapid and lasting pain relief with better quality of life. Although a lot of studies (24-26) have demonstrated good clinical results and life quality improvement achieved by PKP and PVP, there is debate over which of these 2 procedures can provide better efficacy and safety, so we extracted relative data, pooled the outcomes as much as possible, and performed this meta-analysis.

The methodological quality evaluation indicated some limitations to this evidence base. One RCT, 4 prospective comparative, and 3 retrospective cohort articles met the predefined eligibility criteria. The MINORs form and Cochrane Collaboration's Tool for Assessing the Risk of Bias were used to assess the non-RCTs and RCTs, respectively. Most of the studies had poor allocation bias, none of the studies had an unbiased assessment of the study end point, and no trails provided prospective calculation of the sample size. Only one trial (20) reported an adequate sequence generation, and one trial (18) reported allocation concealment. One study (20) used single-blinded outcome assessors. The mean score of non-RCTs on MINORs quality scores was 12.6 (range, 8 - 15), which indicated that there was considerable variability in the evidence base. Therefore although the results of this meta-analysis are deemed appropriate, the methodological assessment risks may have influence on the accuracy and reliability of the pooled results.

Pain relief was measured by VAS score. Although the exact mechanism of pain reduction is unclear, some authors $(27,28)$ indicated that the pain relief was due to the inhibition and immobility of the micromovement in the fractured vertebra. It was also reported that polymethylmethacrylate can destroy the terminal nerve endings in the fractured vertebra and decrease the pain (29). Schofer et al (18) demonstrated that the treatment of PKP and PVP on fresh VCFs can result in significant pain relief. Taylor et al (30) revealed that greater improvement in pain with PKP compared to PVP in their meta-analysis. However, the meta-analysis of clinical comparative studies by Han et al (15) and Xing et al (31) showed no significant difference in pain reduction between PKP and PVP in the short-term and long-term follow-up. The results from subgroup analysis in this meta-analysis showed that PKP has significantly lower VAS scores in the short-term follow-up but not in the long-term follow-up. This showed that the pain relief after PKP treatment was superior to PVP only at shortterm follow-up. However the weakness of the cohort study design and the effect of the natural recovery process could have biased the results, which may diminish the difference in VAS scores between the PKP and PVP in the long-term follow-up.

For functional improvement, PKP appears to be more effective at short- and long-term follow-up in ODI scores. So patients treated with PKP, which has greater injected cement and better kyphosis improvement, can have a better quality of life in the long-run. Besides the ODI, the SF-36 was also used to evaluate the quality of life for VCF patients who received PKP or PVP. We found that both PKP and PVP could significantly improve patients' quality of life compared to pre-operation. PKP seems to be more effective for short- and long-term functional improvements, but no significant difference was found in SF-36 scores between PKP and PVP. The difference of ODI and SF-36 scores in the evaluation of patients' functional improvement may be due to the limited number of studies and lack of RCTs that provided SF-36 scores.

It was demonstrated that both PKP and PVP can restore kyphotic wedge angle (32). In this systematic review, the postoperative kyphosis angle was significantly improved in the PKP group at short-term and long-term follow-up. Patients who underwent PKP had a better kyphosis angle improvement than patients who underwent PVP, and there was slight loss of correction to the angle of kyphosis between short-term and long-term follow-up. The improvement of kyphosis angle by PKP and PVP was partially attributed to patients' prone positioning during operation and partially attributed to subsidence of the 2 endplates of the fractured vertebrae, which was reported in previous studies $(33,34)$. PKP was designed to correct the kyphotic deformity of the fractured vertebra via balloon expansion, so PKP has the potential advantage in restoring vertebral height and correcting kyphotic deformity compared to PVP (35). This is similar to our results, which indicates that PKP is effective in reduction of spinal deformity with VCFs, and patients with severe kyphotic deformity 
or severe OVCFs would be suitable for PKP. One reason for the correction of kyphotic deformity by PKP is the inflatable balloon creates a cavity, which allows more cement to be injected. The pooled results also showed that cement injection was significantly more in PKP than PVP.

Cement leakage is one of the most common complications associated with PKP and PVP. The rate of cement leakage was $9 \%$ after PKP and $41 \%$ after PVP in a systematic review (36), and another recent metaanalysis reported that cement leakage was $7 \%$ in PKP and $20 \%$ in PVP (37). This meta-analysis indicated that PKP has a lower incidence of cement leakage. The lower rate of cement leakage after PKP can be explained as the cement injected in fractured vertebra is a higher viscous form compared to PVP. The inflatable balloon which creates a cavity can compress the cancellous bone into a tight form during PKP, so the cement can be injected into the cavity without great injection pressure (38). During PVP, the cement should fill the gaps between fracture fragments in a less viscous form and under high injection pressure, so it is easier to leak through the defects in the cortex and blood vessels. It was reported that firmer cement during PVP can decrease the risk of cement leakage (39). So patients with vertebral fissures, especially in the posterior edge of the fractured vertebra, are more likely to receive PKP. In addition, the examination method can affect the results of leakage rate. A low cement leakage rate was usually demonstrated by x-ray (29), while a high leakage rate was often demonstrated by computed tomography (CT) scan $(40,41)$. However, all included studies in this metaanalysis showed no case of spinal stenosis or pulmonary embolism caused by cement leakage.

The cemented vertebra can change the biomechanics of the spine and subsequently increase the incidence of new adjacent level VCFs (42). The increased height of the collapsed vertebra increases soft tissue tension around it and can lead to increased load on other vertebra, especially adjacent vertebra. And it has been reported that the rate of developing new VCFs after initial VCFs is 4 times greater than in people without initial VCFs (43). Although it was reported that the risk factors for new adjacent VCFs are higher after PKP than PVP $(44,45)$, a meta-analysis showed the risk of sustained new VCFs after PVP was significantly greater than PKP (37). There was no significant difference in the incidence of new adjacent VCFs between PKP and PVP in this meta-analysis, which was similar to the previous review (31). Because of the small sample size, we could not draw conclusions about this complication, and the insufficient blinding of assessment can affect the results by subjective assessment.

PKP seems to be superior to PVP with regard to short-term pain relief, kyphosis angle correction, cement leakage, and related problems (30). Besides, the improved kyphosis can not only benefit patients' posture but also improve pulmonary function and patients' survival (46). However, a large sample size and high evidence study should be performed in the future to confirm the result.

The limitations of this meta-analysis include statistical efficacy can be improved by more studies, low evidence based non-RCT articles are likely to induce various types of bias, and no accurate definition of short-term and long-term outcome time points.

\section{Conclusion}

This systemic meta-analysis comparing PKP and PVP for the treatment of OVCFs demonstrates that PKP and PVP are both safe and effective procedures. PKP has a similar long-term pain relief, function scores (shortterm ODI scores, short-and long-term SF-36 scores), and new adjacent VCFs in comparison to PVP. PKP is superior to PVP for the injected cement volume, the short-term pain relief, the improvement of short- and long-term kyphotic angle, and lower cement leakage rate. However, PKP has a longer operation time and higher material cost than PVP. To confirm this evaluation, high-quality RCTs should be conducted. 


\section{References}

1. Wasnich RD. Vertebral fracture epidemiology. Bone 1996; 18:179S-183S.

2. Kumar K, Verma AK, Wilson J, LaFontaine A. Vertebroplasty in osteoporotic spine fractures: A quality of life assessment. Can J Neurol Sci 2005; 32:487-495.

3. Schlaich C, Minne HW, Bruckner T, Wagner G, Gebest HJ, Grunze M, Ziegler R, Leidig-Bruckner G. Reduced pulmonary function in patients with spinal osteoporotic fractures. Osteoporos Int 1998; 8:261-267.

4. Ensrud KE, Thompson DE, Cauley JA, Nevitt MC, Kado DM, Hochberg MC, Santora AC 2nd, Black DM. Prevalent vertebral deformities predict mortality and hospitalization in older women with low bone mass. Fracture Intervention Trial Research Group. J Am Geriatr Soc 2000; 48:241-249.

5. Phillips FM. Minimally invasive treatments of osteoporotic vertebral compression fractures. Spine (Phila Pa 1976) 2003; 28:S45-S53.

6. Klotzbuecher CM, Ross PD, Landsman PB, Abbott TA, 3rd, Berger M. Patients with prior fractures have an increased risk of future fractures: A summary of the literature and statistical synthesis. J Bone Miner Res 2000; 15:721-739.

7. Truumees E. Osteoporosis. Spine (Phila Pa 1976) 2001; 26:930-932.

8. Galibert P, Deramond H, Rosat P, Le Gars D. [Preliminary note on the treatment of vertebral angioma by percutaneous acrylic vertebroplasty]. Neurochirurgie 1987; 33:166-168.

9. Garfin SR, Yuan HA, Reiley MA. New technologies in spine: Kyphoplasty and vertebroplasty for the treatment of painful osteoporotic compression fractures. Spine (Phila Pa 1976) 2001; 26:1511-1515.

10. Chandra RV, Yoo AJ, Hirsch JA. Vertebral augmentation: update on safety, efficacy, cost effectiveness and increased survival? Pain physician 2013;16(4):309-320

11. Hoffmann RT, Jakobs TF, Wallnofer A, Reiser MF, Helmberger TK. [Percutaneous vertebroplasty (pv): Indications, contraindications, and technique]. Radiologe 2003; 43:709-717.

12. Wardlaw D, Cummings SR, Van Meirhaeghe J, Bastian L, Tillman JB, Ranstam J, Eastell R, Shabe P, Talmadge $\mathrm{K}$, Boonen S. Efficacy and safety of balloon kyphoplasty compared with nonsurgical care for vertebral compression fracture (FREE): A randomised controlled trial. Lancet 2009; 373:1016-1024.
13. Klazen CA, Lohle PN, de Vries J, Jansen $\mathrm{FH}$, Tielbeek AV, Blonk MC, Venmans A, van Rooij WJ, Schoemaker MC, Juttmann JR, Lo TH, Verhaar HJ, van der Graaf $Y$, van Everdingen KJ, Muller AF, Elgersma OE, Halkema DR, Fransen $H$, Janssens X, Buskens E, Mali WP. Vertebroplasty versus conservative treatment in acute osteoporotic vertebral compression fractures (Vertos II): An openlabel randomised trial. Lancet 2010; 376:1085-1092.

14. Siemionow K, Lieberman IH. Vertebral augmentation in osteoporosis and bone metastasis. Curr Opin Support Palliat Care 2007; 1:323-327.

15. Han S, Wan S, Ning L, Tong Y, Zhang J, Fan S. Percutaneous vertebroplasty versus balloon kyphoplasty for treatment of osteoporotic vertebral compression fracture: A meta-analysis of randomised and non-randomised controlled trials. Int Orthop 2011; 35:1349-1358.

16. Zhou JL, Liu SQ, Ming JH, Peng H, B. Q. Comparison of therapeutic effect between percutaneous vertebroplasty and kyphoplasty on vertebral compression fracture. Chin J Traumatol 2008; 11:42-44.

17. Liu JT, Liao WJ, Tan WC, Lee JK, Liu CH, Chen YH, TB. L. Balloon kyphoplasty versus vertebroplasty for treatment of osteoporotic vertebral compression fracture: A prospective, comparative, and randomized clinical study. Osteoporos Int 2010; 21:359-364.

18. Schofer MD, Efe T, Timmesfeld N, Kortmann HR, Quante M. Comparison of kyphoplasty and vertebroplasty in the treatment of fresh vertebral compression fractures. Arch Orthop Trauma Surg 2009; 129:1391-1399.

19. Yan D, Duan L, Li J, Soo C, Zhu H, Zhang Z. Comparative study of percutaneous vertebroplasty and kyphoplasty in the treatment of osteoporotic vertebral compression fractures. Arch Orthop Trauma Surg 2011; 131:645-650.

20. Endres S, Badura A. Shield kyphoplasty through a unipedicular approach compared to vertebroplasty and balloon kyphoplasty in osteoporotic thoracolumbar fracture: A prospective randomized study. Orthop Traumatol Surg Res 2012; 98:334-340.

21. Kong LD, Wang P, Wang LF, Shen $Y$, Shang ZK, Meng LC. Comparison of vertebroplasty and kyphoplasty in the treatment of osteoporotic vertebral compression fractures with intravertebral clefts.
Eur ] Orthop Surg Traumatol. 2014 Jul;24 Suppl 1:S201-8.

22. Omidi-Kashani F, Samini F, Hasankhani EG, Kachooei AR, Toosi KZ, GolhasaniKeshtan F. Does percutaneous kyphoplasty have better functional outcome than vertebroplasty in single level osteoporotic compression fractures? A comparative prospective study. J Osteoporos 2013; 2013:690329.

23. Ee GW, Lei J, Guo CM, Yeo W, Tan SB, Tow PB, Chen LT, Yue WM. Comparison of clinical outcomes and radiographic measurements in four different treatment modalities for osteoporotic compression fractures: Retrospective analysis. J Spinal Disord Tech. 2013 Nov 6. [Epub ahead of print].

24. Lieberman IH, Dudeney S, Reinhardt MK, Bell G. Initial outcome and efficacy of "kyphoplasty" in the treatment of painful osteoporotic vertebral compression fractures. Spine (Phila Pa 1976) 2001; 26:1631-1638.

25. Perez-Higueras A, Alvarez L, Rossi RE, Quinones D, Al-Assir I. Percutaneous vertebroplasty: Long-term clinical and radiological outcome. Neuroradiology 2002; 44:950-954.

26. McKiernan F, Faciszewski $T$, Jensen R. Does vertebral height restoration achieved at vertebroplasty matter?] Vasc Interv Radiol 2005; 16:973-979.

27. Belkoff SM, Mathis JM, Jasper LE, Deramond $\mathrm{H}$. The biomechanics of vertebroplasty. The effect of cement volume on mechanical behavior. Spine (Phila Pa 1976) 2001; 26:1537-1541.

28. Belkoff SM, Mathis JM, Jasper LE, Deramond $\mathrm{H}$. An ex vivo biomechanical evaluation of a hydroxyapatite cement for use with vertebroplasty. Spine (Phila Pa 1976) 2001; 26:1542-1546.

29. Heini PF, Walchli B, Berlemann U. Percutaneous transpedicular vertebroplasty with PMMA: Operative technique and early results. A prospective study for the treatment of osteoporotic compression fractures. Eur Spine J 2000; 9:445-450.

30. Taylor RS, Fritzell P, Taylor RJ. Balloon kyphoplasty in the management of vertebral compression fractures: An updated systematic review and meta-analysis. Eur Spine ] 2007; 16:1085-1100.

31. Xing D, Ma JX, Ma XL, Wang J, Xu WG, Chen $\mathrm{Y}$, Song $\mathrm{DH}$. A meta-analysis of balloon kyphoplasty compared to percutaneous vertebroplasty for treating osteoporotic vertebral compression frac- 
tures. J Clin Neurosci 2013; 20:795-803.

32. Hiwatashi A, Sidhu R, Lee RK, deGuzman RR, Piekut DT, Westesson PL. Kyphoplasty versus vertebroplasty to increase vertebral body height: A cadaveric study. Radiology 2005; 237:1115-1119.

33. McKiernan F, Jensen R, Faciszewski T. The dynamic mobility of vertebral compression fractures. J Bone Miner Res 2003; 18:24-29.

34. Uppin AA, Hirsch JA, Centenera LV, Pfiefer BA, Pazianos AG, Choi IS. Occurrence of new vertebral body fracture after percutaneous vertebroplasty in patients with osteoporosis. Radiology 2003; 226:119-124.

35. Barr JD, Barr MS, Lemley TJ, McCann RM. Percutaneous vertebroplasty for pain relief and spinal stabilization. Spine (Phila Pa 1976) 2000; 25:923-928.

36. Hulme PA, Krebs J, Ferguson SJ, Berlemann U. Vertebroplasty and kyphoplasty: A systematic review of 69 clinical studies. Spine (Phila Pa 1976) 2006; 31:1983-2001.

37. Eck JC, Nachtigall D, Humphreys SC, Hodges SD. Comparison of vertebroplasty and balloon kyphoplasty for treat- ment of vertebral compression fractures: A meta-analysis of the literature. Spine ] 2008; 8:488-497.

38. Phillips FM, Todd Wetzel F, Lieberman I, Campbell-Hupp M. An in vivo comparison of the potential for extravertebral cement leak after vertebroplasty and kyphoplasty. Spine (Phila Pa 1976) 2002; 27:2173-2178; discussion 2178-2179.

39. Lovi A, Teli M, Ortolina A, Costa F, Fornari $M$, Brayda-Bruno M. Vertebroplasty and kyphoplasty: Complementary techniques for the treatment of painful osteoporotic vertebral compression fractures. A prospective non-randomised study on 154 patients. Eur Spine J 2009; 18:95-101.

40. Yeom JS, Kim WJ, Choy WS, Lee CK, Chang BS, Kang JW. Leakage of cement in percutaneous transpedicular vertebroplasty for painful osteoporotic compression fractures. J Bone Joint Surg $\mathrm{Br}$ 2003; 85:83-89.

41. Heini PF, Orler R. Kyphoplasty for treatment of osteoporotic vertebral fractures. Eur Spine ] 2004; 13:184-192.

42. Tanigawa N, Komemushi A, Kariya S, Kojima H, Shomura Y, Omura N, Sawa- da S. Relationship between cement distribution pattern and new compression fracture after percutaneous vertebroplasty. AJR Am J Roentgenol 2007; 189:W348-W352.

43. Komemushi A, Tanigawa N, Kariya S, Kojima H, Shomura Y, Komemushi S, Sawada S. Percutaneous vertebroplasty for osteoporotic compression fracture: Multivariate study of predictors of new vertebral body fracture. Cardiovasc Intervent Radiol 2006; 29:580-585.

44. Fribourg D, Tang C, Sra P, Delamarter $\mathrm{R}$, Bae $\mathrm{H}$. Incidence of subsequent vertebral fracture after kyphoplasty. Spine (Phila Pa 1976) 2004; 29:2270-2276; discussion 2277.

45. Kim SH, Kang HS, Choi JA, Ahn JM. Risk factors of new compression fractures in adjacent vertebrae after percutaneous vertebroplasty. Acta Radiol 2004; 45:440-445.

46. Strom O, Leonard C, Marsh D, Cooper C. Cost-effectiveness of balloon kyphoplasty in patients with symptomatic vertebral compression fractures in a UK setting. Osteoporos Int 2010; 21:1599-1608. 
